\title{
Lógica dominante de servicio en ecosistemas de negocios artesanales: de la cooperación a la cocreación.
}

\author{
Moisés Rubén Zamora Ramos \\ moises_zamora@uaeh.edu.mx
}

Norma Arely Zuñiga Espinosa

norma_zuniga@uaeh.edu.mx

Universidad Autónoma del Estado de Hidalgo (UAEH)

Pachuca de Soto - México

\section{RESUMEN}

El presente artículo busca direccionar la gestión de negocios artesanales en México, hacia innovadoras teorías de mercadotecnia, lo que permite evolucionar de un enfoque tradicional de cooperación empresarial para la competitividad al marco conceptual de la Lógica dominante del servicio (LDS) y su perspectiva de cocreación en ecosistemas de servicio. El estudio comprende una revisión bibliográfica analítica que esboza y examina las diferencias entre la cooperación, enfoque teórico que aboga por generar una oferta valor del artesano al cliente, y la cocreación, enfoque que propone la generación de valor conjunta entre el artesano y el cliente, presentando el comparativo analítico de la cooperación, como estrategia de competitividad en el sector de las artesanías en México, y las principales premisas de la (LDS), como estrategia de intercambio basado en el servicio para el beneficio mutuo y el desarrollo comunitario. Los autores argumentan que las estrategias de gestión de negocios artesanales deben ser funcionales y adaptadas a la complejidad y particularidades culturales de los pueblos indígenas y de los artesanos. Por lo que resulta relevante proporcionar nuevos conocimientos que permitan a pequeñas y medianas empresas artesanales, generar mejores prácticas de gestión de mercados, respetando su idiosincrasia y asegurando su sostenibilidad.

Palabras clave: lógica dominante de servicio; ecosistema de negocios artesanales; cocreación de valor; cooperación. 


\title{
Service dominant logic in handicrafts business ecosystem: from cooperation to cocreation
}

\begin{abstract}
This article seeks to direct the management of handicrafts businesses in Mexico towards innovative marketing theories, which allows evolving from a traditional approach of business cooperation for competitiveness to the conceptual framework of the ServiceDominant Logic (SD-logic) and its perspective of co-creation in service ecosystems. The study comprises an analytical literature review that outlines and examines the differences between cooperation, a theoretical approach that advocates generating a value offer from the artisan to the customer, with co-creation, an approach that proposes joint value generation between the artisan and customer, presenting the analytical comparison of cooperation, as a competitiveness strategy in the Mexican handicrafts sector, and the main premises of the (SD-logic), as a service-based exchange strategy for mutual benefit and community development. The authors argue that handicraft business management strategies must be functional and adapted to the complexity and cultural particularities of indigenous peoples and artisans. Therefore, it is relevant to provide new knowledge that will allow small and medium-sized artisan enterprises to generate better market management practices, respecting their idiosyncrasies and ensuring their sustainability.
\end{abstract}

Keywords: service-dominant logic; handicrafts business ecosystem; value cocreation; cooperation.

Artículo recibido: 05 octubre. 2021 Aceptado para publicación: 02 noviembre 2021 Correspondencia: moises_zamora@uaeh.edu.mx Conflictos de Interés: Ninguna que declarar 


\section{INTRODUCCIÓN}

Los negocios artesanales son aquellos que surgen de la venta de artesanías en México y en el mundo, estos negocios suelen ser micro a medianos negocios emprendidos por los artesanos, provenientes mayormente de pueblos indígenas. En este negocio artesanal, predomina el autoconsumo de artesanías entre los pueblos indígenas y la elaboración de productos para el consumidor nacional o internacional, donde existe una apreciación por la cultura detrás del bien, para el productor (artesano) y/o la región de donde es tradición, de esta forma, las artesanías son objetos o productos de identidad cultural comunitaria. De acuerdo con la Organización de las Naciones Unidas para la Educación, la Ciencia y la Cultura (UNESCO) el dominio de las técnicas tradicionales de patrimonio comunitario es lo que permite al artesano crear diferentes objetos de variada calidad, imprimiendo los valores simbólicos e ideológicos de la cultura local (UNESCO, 1997).

Actualmente, los negocios de artesanías han tenido que enfrentarse a mercados globalizados y clientes exigentes, además de numerosas y aceleradas innovaciones generando una creciente dependencia de la supervivencia del artesano hacia los consumidores. Esto ha generado que, a pesar de ser productos con características culturales diferenciadoras, se observa un panorama difícil y desalentador para el artesano. Se observa cada día más que el cliente no valora el producto y solicita un descuento u ofrece un precio mínimo, práctica comercial conocida como regateo. Este fenómeno se observa en toda la cadena de comercialización desde el cliente, el mayorista, el punto de venta y el comercializador de artesanías, reflejando el poco valor que se le da a las artesanías provenientes del productor (Sales, 2013).

La comercialización de artesanías tiene un impacto en los diferentes papeles o roles que tienen los artesanos y pueblos indígenas en la sociedad, sin embargo, a pesar de que México cuenta con una amplia variedad de productos artesanales, a menudo no se valoran desde una perspectiva de riqueza cultural, y como consecuencia para los pueblos indígenas. Las prácticas artesanales están quedando en el olvido, teniendo un impacto negativo en los ingresos de los productores artesanales y en la sobrevivencia de su cultura. Además de ser vistos como agentes económicos y generadores de empleo en miles de familias, los artesanos portan saberes y tradiciones que los ubican como un patrimonio cultural viviente (Sales, 2013). Lo cual genera el interés por encontrar un esquema de negocio integral basado en las innovaciones de mercadotecnia sostenible, que les permita 
competir en el mundo globalizado, sin dejar sus prácticas tradicionales o sin perder su valor cultural al momento de elaborar y/o comercializar sus productos artesanales.

En respuesta a esta problemática, los negocios artesanales han buscado implementar estrategias de mercadotecnia basadas en las teorías clásicas de competitividad, mediante la búsqueda de una ventaja competitiva y un atributo diferenciador, tal como las grandes empresas de sectores como la tecnología, la industria manufacturera o la alimentación han implementado, sin embargo estas teorías de competitividad, no consideran la idiosincrasia de los pueblos indígenas, tampoco han logrado comprender su cosmovisión y los objetivos que persiguen al vender productos artesanales, ya que los artesanos no solo tiene objetivos comerciales, sino de preservación de su cultura. En este sentido, la propuesta de cambio de un enfoque en el que el valor es ofertado, por uno en el que el valor es cocreado entre los diferentes actores, surge ante la perspectiva de la mercadotecnia bajo la Lógica dominante del servicio (LDS) donde se deja atrás las teorías tradicionales de percibir los productos y los servicios en una clasificación de tangibilidad e intangibilidad.

La Lógica revisada de los recursos intangibles en el servicio enfatiza que el valor se logra sólo cuando está en uso y es cocreado por el cliente junto con los artesanos, de ahí que este proceso de cocreación debe ser entendido como un proceso dinámico, multifactorial y con una complejidad cultural intrínseca. Con base a esto, es crucial entender por qué y cómo se genera valor entre los negocios artesanales y los clientes, para evaluar los roles de los actores, incluyendo su propia participación. Las premisas de la lógica dominante del servicio, como estrategia de intercambio basado en el servicio para cocrear valor el cliente y el artesano, favorecerá el desarrollo comunitario de los pueblos indígenas al preservar sus tradiciones y ser agentes económicos al poder dar un producto de intercambio que será símbolo de un valor. El cual no solo estará centrado únicamente en el producto artesanal, si no en el valor en uso que acompaña a la artesanía.

Al emplear la teoría de la (LDS) y la cocreación de valor, surge una oportunidad para los artesanos de cerrar la brecha existente entre las actuales estrategias de marketing basadas en la competitividad entre las industrias, con la compleja naturaleza de los negocios de artesanías, al adoptar un enfoque que busca involucrar al cliente en la generación de valor con el artesano y los demás agentes del ecosistema de negocio al comercializar artesanías. 
La competitividad ha estado en la mente de los economistas por años, quienes han generado teorías que van desde el enfoque de Adam Smith y Michael Porter, este último con sus aportaciones a la estrategia competitiva en 1985, la ventaja competitiva de las naciones en 1989, Clústers y competitividad 1990. De donde surge la conceptualización, que una empresa es competitiva en términos de rentabilidad o su capacidad de crear valor (Porter, 1990), con habilidades y áreas de conocimiento que se comparten entre las unidades de negocio, así como el resultado de la integración y armonización de la competencia estratégica (Javidan, 1998).

Este enfoque de competitividad ha establecido que el desarrollo y competitividad empresarial, se logra cuando se atienden las necesidades del consumidor y se compite con las demás unidades de negocio, mediante una ventaja competitiva para mantener relaciones mutuamente satisfactorias con los grupos de interés (Ferrel y Hartline, 2012). Bajo estas premisas, el desarrollo económico se ha vuelto un tema cada vez más importante y común, de extensa aplicabilidad entre diferentes sectores económicos a nivel internacional, considerando que entre los actores económicos independientes de una industria se establecen de manera espontánea diferentes tipo de acuerdos de colaboración para desarrollar acciones que apuntan a resultados comunes, mismos que no podrían lograr si actuaran de forma aislada, lo cual permite una apertura de colaboración económica entre diversas empresas que buscan un fin en común, mayormente de participación de mercado, rentabilidad y posicionamiento (Dini, 2010;Sánchez, González y Jiménez, 2007).

Sin embargo, el enfoque de cooperación entre las empresas para competir entre ellas no ha resultado del todo aplicable para la cultura que enmarca los negocios artesanales en México, ya que los artesanos, quienes provienen mayormente de pueblos indígenas, distan ampliamente en ideología con un empresario, ya que los objetivos de venta y distribución de artesanías obedecen a una cosmovisión de sus comunidades indígenas, la cual es diferente a una cultura empresarial genérica. Es por ello que se identifica esta brecha conceptual entre la vasta teoría clásica aplicable para diversos sectores económicos y la limitada literatura del marketing que aborde la gestión de negocios artesanales, considerando su cultura y autoconcepto de "éxito empresarial" (García Canclini, 1999). 
En este contexto, emerge la necesidad de generar mejores prácticas dentro del negocio artesanal en México a través del enfoque de la (LDS), considerando la complejidad del ecosistema que integran los pueblos indígenas cuando producen y comercializan artesanías. Esta teoría se centra en la creación conjunta de valor (cocreación de valor), denotando que, durante el intercambio de valor basada en el servicio, los negocios de artesanías no ofrecen valor al cliente, sino proponen valor, y los clientes tienen un papel primordial participando activamente para lograr ese valor esperado. La (LDS) va más allá de la orientación al consumidor del marketing, e implica una colaboración constante entre los artesanos y el cliente, de modo que estas organizaciones aprenden de sus clientes y de sus necesidades, pero también los clientes aprenden de los artesanos y el significado y valor cultural de las artesanías como uso social de patrimonio cultural (Vargo y Lusch, 2004, 2008, 2016).

Los autores generan un acercamiento teórico para comprender el servicio como base del intercambio, entendiendo el servicio como la integración de recursos y sus implicaciones en el sector de las artesanías en México. Este trabajo se centra en destacar la relevancia que la cocreación tiene en los negocios artesanales, más allá de la cooperación, premisa que se ha aplicado hasta ahora con debatibles resultados específicamente en este sector, específicamente los autores se centran en vincular teóricamente las premisas de la (LDS) (Vargo y Lusch 2017), para pasar de cooperación a la cocreación de valor para guiar la gestión estratégica del mercado de artesanías, debido a la perspectiva integral que dicha teoría para con el ecosistema de servicio.

La revisión literaria presentada, busca destacar la aplicabilidad de la (LDS) en la gestión de los negocios artesanales, con la finalidad de construir nuevo conocimiento que permita encontrar caminos más precisos para entender un modelo de negocio que se adapte a crear valor dentro de todos los actores que intervienen en los ecosistemas de negocio de artesanía, pasando de un esquema de cooperación y competencia tradicional a un esquema de cocrear valor cultural para todos los actores del ecosistema, incluido el comprador.

\section{ESTRATEGIAS METODOLÓGICAS O MATERIALES Y MÉTODOS}

Se realiza una revisión de la literatura, partiendo de una investigación secundaria basada en la búsqueda del desarrollo y evolución teórica de los ejes principales, en bases de datos de artículos académicos, utilizando plataformas como Web of Science, SCOPUS, 
Emerald insight, EBSCO Information Services y Google Scholar, en su mayoría artículos científicos obtenidos bajo acceso público y licencias otorgadas por instituciones de educación superior. Posteriormente se presenta un comparativo de aplicabilidad entre el enfoque de cooperación empresarial para la competitividad y Lógica dominante de servicio, en el ecosistema de los negocios de artesanías en México, sentando las bases que permitan un cambio de estrategia de gestión, de la cooperación empresarial hacia la cocreación de valor para el desarrollo comunitario.

\subsection{Pueblos indígenas de México}

Los pueblos indígenas han conservado características sociales, culturales, económicas y políticas que son distintas a las de las sociedades dominantes en las que viven. A pesar de sus diferencias culturales, los diversos grupos de pueblos indígenas de todo el mundo comparten problemas comunes relacionados con la protección de sus derechos como pueblos distintos, lo que incluye la elaboración y comercialización de artesanías como medio de vida e instrumento de preservación cultural (ONU, 2021).

Los productos artesanales son hechos mediante procesos manuales o auxiliados por herramientas manuales o incluso el uso de maquinaria, siempre que la contribución manual directa del artesano siga siendo el componente más importante del producto acabado y la materia prima básica transformada generalmente es obtenida en la región donde habita el artesano (Robles, Romero y García, 2007). Por lo tanto, la artesanía se crea como producto duradero o efímero, y su función original está determinada en el nivel social y cultural; en ese sentido, pueden destinarse para el uso doméstico, ceremonial, ornato, vestuario o bien, como implemento de trabajo. Donde su producción es sin limitación por lo que se refiere a la cantidad y utilizando materias primas procedentes de recursos sostenibles (UNESCO, 1997).

México es un país con una amplia variedad de cultura, pueblos indígenas y artesanías, que se encuentran en prácticamente todo el territorio nacional. Partiendo de la cultura de los productores indígenas, quienes presentan condiciones culturales que dotan de valor diferenciador a sus productos desde la perspectiva que poseen de la vida y el mundo (cosmovisión) la cual se plasma en las artesanías que elaboran y le dan un valor diferenciador, por lo tanto, su objetivo de su elaboración y comercialización no es exclusivamente comercial. 
En este complejo y particular entorno comercial-cultural, es posible decir que la actividad artesanal viene sustentada por una carga idiosincrática muy fuerte y propia de cada región, con objetivos muy específicos de los pueblos indígenas, mismos que se presentan en la Figura 1. Es decir, que dentro de la conceptualización de las artesanías tradicionales existe un sustento emotivo, religioso y a veces cosmogónico." que van más allá de la comercialización, la competitividad y la rentabilidad (Sales, 2013; Robles, Romero y García, 2007; Hernández, Domínguez, y Ramos, 2002; UNESCO, 1997).

Aunado a lo anterior, no se puede hablar de una homogeneización de diferencias y riquezas culturales entre los pueblos indígenas ni nacional o internacional, ya que existen 476 millones de pueblos indígenas que viven en 90 países de todo el mundo, lo que representa el 6,2\% de la población mundial (ONU, 2021). Estos pueblos indígenas de todo el mundo han buscado el reconocimiento de sus identidades, sus formas de vida y su derecho a las tierras, territorios y recursos naturales tradicionales por años; sin embargo, a lo largo de la historia, siempre se han violado sus derechos, siendo posiblemente, uno de los grupos de personas más desfavorecidos y vulnerables en el mundo. En el sector económico, la visibilidad no ha sido mejor, ya que el conocimiento de su visión es limitado, de tal forma que la tendencia de gestión que aboga por la estandarización ha sido ampliamente sugerida, e implementada con cuestionables resultados.

La comunidad internacional reconoce ahora que se requieren medidas especiales para proteger los derechos de los pueblos indígenas del mundo, incluidos su derecho a comercializar y proteger sus artesanías (ONU, 2021). Es por ello por lo que la Organización Internacional del Trabajo (OIT) protege la profesión del artesano con el Convenio 169 sobre pueblos indígenas y tribales de la OIT, donde se destinan 3 artículos a la formación profesional, artesanía e industrias rurales. Destacando el artículo 23.1 el que refiere a las actividades tradicionales relacionadas con la economía de subsistencia de los pueblos interesados, deberán reconocerse como factores importantes del mantenimiento de su cultura, de su autosuficiencia y desarrollo económicos (OIT, 1989). 
Figura 1. Objetivos de los pueblos indígenas al elaborar artesanías

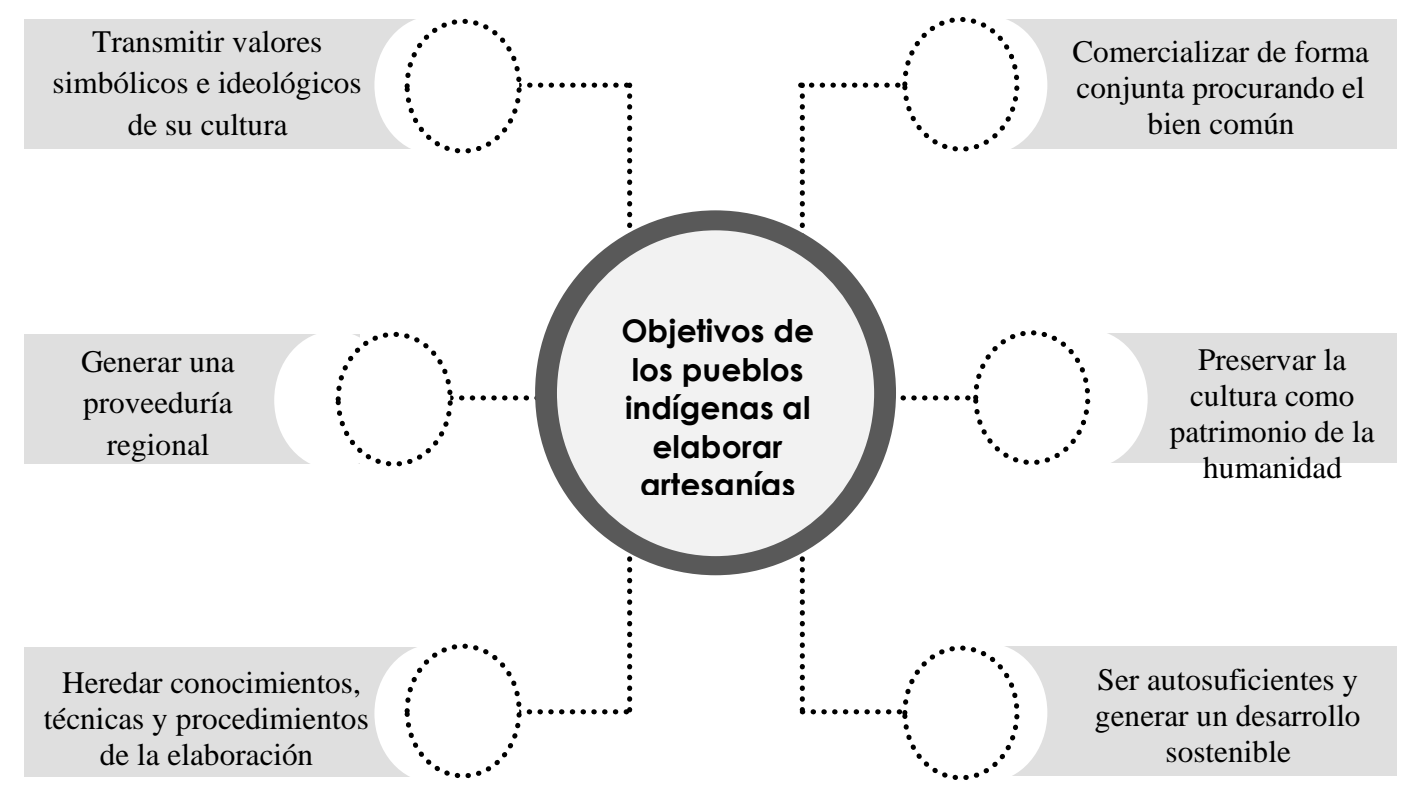

Elaboración propia con base en (Jiménez, Domínguez y Martínez, 2009; Robles,

Romero y García, 2007; Hernández, Domínguez y Ramos, 2002 y UNESCO, 1997).

Aun cuando la comunidad internacional reconoce la imperante necesidad de valorizar a las comunidades indígenas, los artesanos siguen luchando por su autonomía cultural, con la finalidad de preservar y desarrollar la identidad cultural étnica y no crear una libre determinación etnoterritorial (ONU, 2021). En este sentido, los esquemas de competitividad tradicionales no consideran que existen negocios como la artesanía cuya finalidad no es competir con otras empresas de artesanías, con el mercado global o estar en tendencia, sencillamente buscan un intercambio de valor entre el artesano y el cliente de la artesanía ya que el bien es visto como un conducto que ayuda a preservar la identidad cultural del artesano y su comunidad (Jiménez, Domínguez y Martínez, 2009; Robles, Romero y García, 2007; Hernández, Domínguez y Ramos, 2002).

\subsection{Enfoque de la cooperación empresarial y competitividad}

\subsubsection{Volumen de producción y venta para lograr una mayor competitividad y rentabilidad}

Los negocios de artesanías han sido vistos desde el enfoque teórico clásico de la competitividad (Hernández, Domínguez y Ramos,2002;), donde un negocio o empresa es competitivo en su forma más simple en términos de rentabilidad o capacidad de crear 
valor, por medio de sus habilidades y áreas de conocimiento integradas, para lograr una competencia estratégica (Porter, 1990 y Javidan, 1998).

Desde el enfoque del marketing, las estrategias de mercadotecnia consisten en una planeación estratégica donde las empresas (negocios) usarán sus fortalezas y habilidades, para equilibrarlas con las necesidades y requerimientos de los clientes. Siendo el área de mercadotecnia estratégica, la que planea acciones a largo plazo que deriven en la habilidad de construir empresas o productos competitivos (Ferrel y Hartline, 2012). Bajo esa lógica, el éxito comercial de las empresas dependerá de captar, mantener y aumentar el número de clientes, debido a que el cliente es el único verdadero centro de ganancias, debido a que, sin clientes, las empresas no pueden expandir su nivel de producción para construir una fábrica, contratar empleados, programar juntas e involucrarse en cualquier actividad empresarial. De modo que, sin clientes no hay negocio (Kotler y Keller, 2012; Kotler y Armstrong, 2012).

\subsubsection{Cooperación económica para lograr una competitividad reflejada en la participación de mercado}

Las empresas impulsan estrategias competitivas basadas en relaciones de colaboración recíproca mejor conocida como cooperación empresarial para desarrollar acciones que apuntan a resultados que no podrían lograr si actuaran de forma aislada (Dini, 2010, Arcas, Hernández y Munuera, 2000). Está cooperación empresarial, es una vinculación entre empresas independientes, la cual puede estructurarse de varias maneras; según el número de participantes o su posición en la cadena productiva de pertenencia (Dini, 2010), con la finalidad de asociar fuerzas, compartir recursos y reducir riesgos entre empresas (Echeverría, Aguirre y Aparicio, 2014).

En este contexto, emerge el esquema de colaboración empresarial, conceptualizado como la acción de trabajar juntamente con otra empresa u otras para un mismo fin común. En relación con lo anterior, se entiende que dos o más empresas pueden establecer acuerdos de cooperación cuando cada una posee un valor añadido en una etapa de la cadena de valor y de forma conjunta pueden mejorar su posición competitiva al ser más eficientes (Sánchez, González y Jiménez, 2007). Existen diferentes modalidades o tipos de cooperación empresarial desde un enfoque financiero, comercial, jurídico y por acuerdos entre organizaciones, los cuales se resumen en la Figura 2. El modelo de colaboración comercial está relacionado a la mercadotecnia, se fundamenta en acuerdos comerciales 
ejemplo de ello es la venta compartida (piggy-back) que es una fórmula de cooperación que facilita las ventas en el extranjero haciendo uso de una red de distribución en otros países. De igual modo existen las regulaciones de denominación de origen, franquicias, licencias de patentes y marcas, que tienen relación con la mercadotecnia (Ciria, M., 2014). En ese sentido, las asociaciones regionales de empresas mejoran la colaboración tanto en el plano formal como informal, porque se convierten en un elemento fundamental a la hora de obtener influencia y legitimidad por parte de las empresas ante las administraciones públicas, que permite conseguir ayudas públicas o cambios legales (Porter, 1998). Aunado a lo anterior, se pueden identificar las cooperativas, organizaciones de carácter democrático que buscan colaboración entre los cooperativistas (agrupaciones de empresas o individuos) y con la sociedad.

Por otro lado, la sociedad cooperativa es una forma de organización social integrada por personas físicas con base en intereses comunes y en los principios de solidaridad, esfuerzo propio y ayuda mutua, con el propósito de satisfacer necesidades individuales y colectivas, a través de la realización de actividades económicas de producción, distribución y consumo de bienes y servicios (Cámara de Diputados del H. Congreso de la Unión, 2009). La cooperación comercial de negocio a negocio, entre las redes y las agrupaciones cooperativas ha desempeñado un papel importante dentro de una economía globalizada que busca competitividad.

Figura 2. Modelos de competitividad empresarial

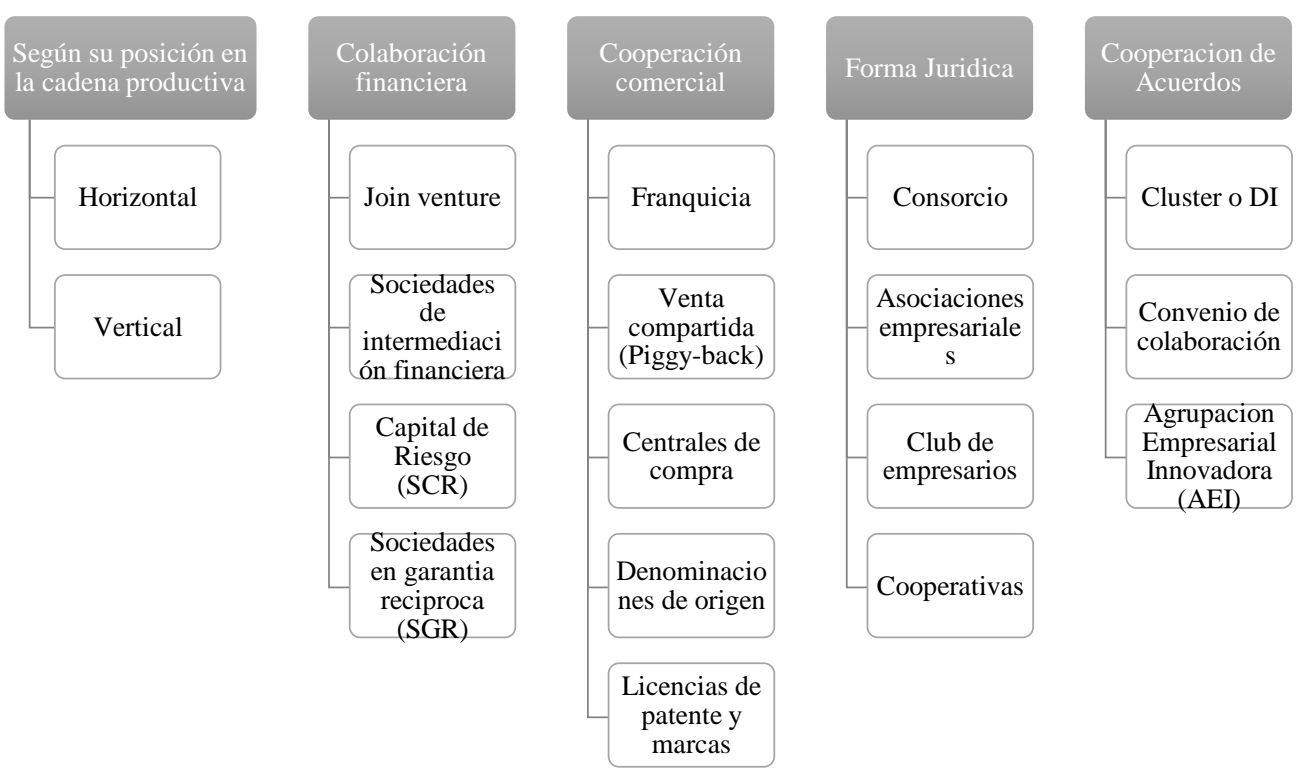

Elaboración propia, basado en Ciria, M. (2014) y Dini, M. (2010). 


\subsubsection{Ventaja competitiva para la rentabilidad empresarial}

La dinámica económica de competitividad se centra cada vez más en una combinación de factores entre los cuales se pueden identificar como; calidad, capacidad de innovación, modalidades de distribución, identificación y orientación hacia los gustos de los consumidores, precio y servicios post ventas, entre otros. Para lograr esta ventaja competitiva se requiere un conjunto de competencias que proceden tanto de los ámbitos manufactureros como de la investigación y desarrollo, la distribución, la comercialización y la gestión financiera, siendo vital que la empresa busque la colaboración empresarial para poder cumplir con las necesidades y cambios en el mercado (Dini, 2010; Kotler y Keller, 2012).

Cuando se habla de ventaja competitiva, se consideran los términos de diferencias objetivas, algo que la empresa hace mejor que sus competidores, que le otorga superioridad para satisfacer las necesidades de los clientes o para mantener relaciones mutuamente satisfactorias con los grupos de interés importantes (Ferrel y Hartline, 2012). Estas ventajas derivan de las fortalezas que la empresa posee o de las debilidades de las empresas rivales. Las estrategias empresariales genéricas permiten que las organizaciones obtengan una ventaja competitiva a partir de tres ejes fundamentales: liderazgo en costos (enfatiza la producción de bienes estandarizados a un costo unitario muy bajo), diferenciación (producir bienes y servicios considerados únicos) y enfoque (producir bienes y servicios que cubran las necesidades de pequeños grupos de consumidores (Porter, 1997; Peña y Garrido, 2016).

\subsubsection{El intercambio de valor se da durante la transacción entre el ofertante y el}

\section{demandante}

El único valor que la empresa es capaz de generar, es aquel que se deriva de los clientes, por ello las ventajas competitivas deben orientarse a la estrategia comercial de la empresa, la mercadotecnia integra las actividades de exploración de valor, generación de valor y entrega de valor con el propósito de generar relaciones de largo plazo mutuamente satisfactorias y una prosperidad compartida entre los interesados clave en el negocio considerando la administración de una cadena de valor superior que proporciona un alto nivel de calidad en términos de producto, servicio y rapidez y logra un crecimiento rentable al expandir su participación de clientes, construir lealtad de los clientes, y capturar el valor de vida del cliente (Kotler y Keller, 2012; Constantinides, 2006; ). 
Cuando los clientes ven todos los productos que la competencia ofrece con las mismas características y beneficios, sus decisiones de compra son impulsadas principalmente por el precio. Igualmente, la estrategia de fijación de precios es un elemento importante para considerar dentro de la demanda del producto, porque puede suceder que una empresa cubra sus costos, pero eso no significa que los clientes pagarán por esos precios (Ferrel y Hartline, 2012).

El valor percibido por el cliente se basa en la diferencia entre los beneficios que el cliente obtiene y los costos en que incurre. Aumentar el valor de la oferta para el cliente, es incrementar los beneficios económicos, funcionales o emocionales, y/o al reducir uno o más costos. Acrecentar la satisfacción del cliente al disminuir los precios o aumentar los servicios podría producir menores ganancias (Kotler y Keller, 2012).

\subsubsection{Oferta de valor como satisfactor de necesidades}

La mercadotecnia es un proceso social por el cual tanto grupos como individuos obtienen lo que necesitan y desean, mediante la creación de oferta y libre intercambio, entre productos y servicios de valor con otros grupos e individuos (Kotler y Keller,2012; Kotler y Armstrong, 2012; Constantinides, 2006), buscando un equilibrio para que la rentabilidad de la empresa no se vea afectada y pueda seguir manteniendo los ingresos del cliente (Kotler y Keller, 2012).

Desde el anterior enfoque, los productos no se crean ni se venden como elementos individuales, sino que se desarrollan y se venden como ofertas. La oferta de producto con frecuencia se integra con muchos elementos diferentes; por lo general, son una combinación de productos tangibles, servicios, ideas, imágenes o incluso personas (Ferrel y Hartline, 2012). Los productos son cualquier cosa que pueda ser ofrecida a un mercado para satisfacer un deseo o necesidad, incluyendo bienes físicos, servicios, experiencias, eventos, personas, lugares, propiedades, organizaciones, información e ideas (Kotler y Keller, 2012).

Existen diversos factores que subrayan el valor del cliente, así como la creación de empresas orientadas al mercado, flexibles e inventivas, capaces de innovar y adaptarse a las cambiantes condiciones del mercado que le permita ser más competitivos de manera conjunta con aliados estratégicos, grupo de empresas o proveedores clave, considerando satisfacer las necesidades del cliente (Kotler y Keller, 2012; Constantinides, 2006; Ferrel, O. y Hartline, M., 2012). Se puede decir que la principal premisa es que las empresas 
utilizan sus recursos para generar valor y ofrecerlo al cliente, para satisfacer sus necesidades o impulsar sus deseos.

\subsection{Lógica dominante de servicio (el valor no se oferta, se cocrea)}

Dentro de un contexto empresarial cada vez más complejo y con mayor compromiso hacia la sostenibilidad, la gestión estratégica de mercadotecnia en el mercado de las artesanías ha sido los últimos años un determinante en el desarrollo y madurez del negocio (Zúñiga, Toro y Gámez, 2016; Cantillo Campo, Paz Marcano y Ojeda Hidalgo, 2021; Guatzozón Maldonado, Canto Esquivel y Pereyra Chan, 2020). Dentro de las nuevas teorías que han evolucionado a la mercadotecnia, se encuentra la Lógica dominante de servicio, un enfoque innovador que explica el intercambio de valor basado en el servicio, cambiando el paradigma tradicional en la gestión del mercado, en la que el vendedor genera una oferta de valor mediante un bien, por un enfoque centrado en el servicio como el principal medio para cocrear valor, sugiriendo que el intercambio en el mercado es el proceso en el que los actores integran sus conocimientos en beneficio mutuo (Lusch y Vargo, 2006; Lusch, Vargo y O’brien, 2007; Vargo y Lusch, 2008; Vargo y Lusch, 2014; Vargo y Lusch, 2017; Vargo, Lusch, Akaka y He, 2020).

Esta relativamente nueva forma de entender la mercadotecnia tiene sus antecedentes desde los años 80 's cuando el marketing de servicios nace como área en estudio de la disciplina, sin embargo, actualmente no es únicamente una rama de la mercadotecnia, sino que se ha convertido en una perspectiva que ha sido aplicada extensamente en diversas disciplinas (Vargo y Lusch, 2017). Como un enfoque en consolidación de la mercadotecnia, considera que el servicio en sí mismo, es fundamental para el intercambio económico y la generación de valor, sin centrarse en los bienes como tradicionalmente se ha realizado, sin dejar de lado el papel central de los bienes durante la dinámica del servicio. De esta forma, los precursores del enfoque sostienen que el valor es generado por múltiples actores durante el servicio, mediante una coproducción, especialmente cuando los bienes están implicados en la creación de este valor (Vargo y Akaka, 2009), La (LDS) deja atrás la tradicional conceptualización de la división entre servicio y producto por su naturaleza de tangibilidad e intangibilidad, por el contrario, este enfoque aboga por que el servicio puede prestarse de forma directa o indirecta, a través de un bien, como un producto intangible. Dentro de sus principales características, se encuentra la premisa de basar el intercambio en el servicio, mediante un proceso dinámico de 
cocreación por parte de todos los actores y recursos del ecosistema; 1) recursos operativos (competencias, aprendizajes y conocimientos) y 2) recursos operantes, sobre los que se ejerce una actuación para lograr el beneficio (recursos naturales, bienes y dinero) (Vargo y Lusch 2004; Kotler, Pfoertsch y Sponholz, 2021). De esta forma, el principal eje de la (LDS) es la cocreación de valor, abogando por cambiar la perspectiva clásica en la que la empresa genera una oferta de valor, por cocrear con el cliente el valor del intercambio.

\subsubsection{Cocreación de valor en ecosistemas de servicio}

En este entorno global de servicio, diversas industrias han adoptado la teoría de (LDS) juntamente con el enfoque de cocreación de valor en ecosistema de servicio, para mejorar su gestión estratégica y asegurar la sostenibilidad de sus negocios. Esto se debe a que dicho enfoque, (concepto de servicio basado en la teoría del ecosistema de servicio) está centrado en la generación de valor de forma conjunta entre todos los actores del ecosistema, no de forma idéntica, pero si activamente (Nie, Zurlo, Camussi \& Annovazzi, 2019). La teoría de ecosistema de servicios en los negocios es un concepto tomado de la biología para entender mejor las interacciones entre actores (componentes vivos) y factores (componentes no vivos) como miembros de un todo, generando como resultado de su interacción con la colaboración, un valor cocreado (Díaz-Méndez, Saren y Gummesson, 2017).

Estos ecosistemas han sido definidos por Lusch y Vargo (2014, p. 24) como un "sistema relativamente autónomo y autoajustable de agentes integradores de recursos conectados por acuerdos institucionales compartidos y por la creación mutua de valor a través del intercambio de servicios." El concepto anterior enfatiza el dinamismo del servicio y la participación de todos sus actores y arreglos institucionales, generando valor para sí mismos y para otros, así como su contribución al funcionamiento y sostenibilidad del ecosistema (Lusch, Vargo y Gustafsson, 2016). El análisis de estos actores y sus interacciones e intercambios dependerá de cada complejidad del ecosistema y sus particularidades, con el objetivo de realmente cocrear valor entre todos sus actores incluido el comprador.

Mientras la gestión de la mercadotecnia sigue evolucionando hacia una lógica de intercambio basada en el servicio como se muestra en la (Tabla.1), en la cual sé aboga por una comprensión sistémica de la creación de valor y la influencia del contexto en el que se desarrolla el valor de uso. De ahí que la cocreación de valor se entienda como una 
estrategia de marketing y gestión que se centra en involucrar al cliente para generar valor de forma innovadora y natural (Perks, Gruber, y Edvardsson, 2012), cambiando la visión tradicional de la relación productor-cliente, que hasta ahora no parece ser la idónea para la industria de las artesanías, debido al valor cultural y la representatividad regional que tienen las artesanías, no solo para los artesanos, sino también para los clientes.

Tabla 1. Cocreación de valor en ecosistemas de servicio desde la perspectiva teórica del (LDS)

\begin{tabular}{|c|c|c|c|c|c|}
\hline Núm. & Investigación & Propuestas fundamentales & Investigador & Revista & $\begin{array}{l}\text { Número } \\
\text { de Citas }\end{array}$ \\
\hline 1 & $\begin{array}{l}\text { Evolving to a } \\
\text { new dominant } \\
\text { logic for } \\
\text { marketing }\end{array}$ & $\begin{array}{l}\text { Cambio de paradigma de la } \\
\text { tradicional lógica dominante } \\
\text { del producto a la lógica } \\
\text { dominante del servicio }\end{array}$ & $\begin{array}{l}\text { Vargo, S. L., } \\
\text { y Lusch, R. } \\
\text { F. (2004) }\end{array}$ & $\begin{array}{l}\text { Journal of } \\
\text { marketing. }\end{array}$ & 18802 \\
\hline 2 & $\begin{array}{l}\text { Service- } \\
\text { dominant logic: } \\
\text { reactions, } \\
\text { reflections, and } \\
\text { refinements. }\end{array}$ & $\begin{array}{l}\text { Naturaleza y el alcance de la } \\
\text { lógica S-D, como cocreación } \\
\text { de una filosofía centrada en el } \\
\text { servicio por parte de la } \\
\text { comunidad mundial del } \\
\text { marketing. }\end{array}$ & $\begin{array}{c}\text { Lusch, R. F., } \\
\& \text { Vargo, S. } \\
\text { L. (2006) }\end{array}$ & $\begin{array}{c}\text { Marketing } \\
\text { theory. }\end{array}$ & 2550 \\
\hline 3 & $\begin{array}{l}\text { Service- } \\
\text { dominant logic: } \\
\text { continuing the } \\
\text { evolution }\end{array}$ & $\begin{array}{l}\text { Actualiza las premisas } \\
\text { fundacionales abordando y } \\
\text { clarificando las implicaciones } \\
\text { de la teoría. }\end{array}$ & $\begin{array}{l}\text { Vargo, S. L., } \\
\text { \& Lusch, R. } \\
\text { F. (2008) }\end{array}$ & $\begin{array}{l}\text { Journal of } \\
\text { the } \\
\text { Academy of } \\
\text { marketing } \\
\text { Science. }\end{array}$ & 8558 \\
\hline 4 & $\begin{array}{l}\text { Service- } \\
\text { Dominant Logic } \\
\text { as a Foundation } \\
\text { for Service } \\
\text { Science: } \\
\text { Clarifications }\end{array}$ & $\begin{array}{l}\text { Se fundamenta la aplicación } \\
\text { de competencias en beneficio } \\
\text { de otro- es la base de todo } \\
\text { intercambio, así como las } \\
\text { características principales de } \\
\text { la cocreación }\end{array}$ & $\begin{array}{l}\text { Vargo, S. L., } \\
\text { \& Akaka, M. } \\
\text { A. (2009) }\end{array}$ & $\begin{array}{l}\text { Servicie } \\
\text { Science. }\end{array}$ & 690 \\
\hline 5 & $\begin{array}{c}\text { Service- } \\
\text { dominant logic: } \\
\text { What it is, what } \\
\text { it is not, what it } \\
\text { might be }\end{array}$ & $\begin{array}{l}\text { Explora la idea de un } \\
\text { coproductor en la primera } \\
\text { fase del proceso de creación } \\
\text { de valor: el proceso de } \\
\text { identificación de las } \\
\text { necesidades del cliente. }\end{array}$ & $\begin{array}{l}\text { Vargo, S. L., } \\
\text { \& Lusch, R. } \\
\text { F. (2014) }\end{array}$ & $\begin{array}{l}\text { The service- } \\
\text { dominant } \\
\text { logic of } \\
\text { marketing. }\end{array}$ & 1260 \\
\hline 6 & $\begin{array}{l}\text { Service- } \\
\text { dominant logic } \\
2025\end{array}$ & $\begin{array}{l}\text { Se fundamenta la LDS en } 6 \\
\text { Axiomas hacia una teoría } \\
\text { general de la cocreación de } \\
\text { valor y el macromarketing }\end{array}$ & $\begin{array}{l}\text { Vargo, S. L., } \\
\text { \& Lusch, R. } \\
\text { F. (2017) }\end{array}$ & $\begin{array}{l}\text { International } \\
\text { Journal of } \\
\text { Research in } \\
\text { Marketing. }\end{array}$ & 876 \\
\hline
\end{tabular}

Elaboración propia con base en (Vargo y Lusch, 2017) 
El actual enfoque busca generar cocreación de valor, para lo cual resulta relevante no dar por sentado que se conoce las necesidades de los clientes de manera ideal y en consecuencia "ofrecer valor", sino cocrear este valor, para lo cual es necesario no solo conocer factores del consumo, sino involucrar al cliente con mayor participación e interacción durante la producción, comercialización y el valor uso, logrando un resultado más integral, que no se limite a generar una oferta de valor sino obtenerlo de forma conjunta (Dollinger, Lodge, y Coates, 2018).

Las estrategias de mercadotecnia que buscan generar un intercambio basado en el servicio integran en su estructura dos elementos dependientes: el servicio -la aplicación de los recursos propios en beneficio de todos los actores del intercambio-; y b) el valor es siempre cocreado. En este sentido, recientemente Vargo, Akaka, y Vaughan (2017) conceptualizan el valor desde la perspectiva del ecosistema de servicios, considerando características específicas, mencionando que el valor es fenomenológico; lo que implica que lo que es valioso para un actor en un lugar y tiempo puede no serlo para otro actor o ese mismo actor en otro momento y lugar (Vargo, Maglio, y Akaka, 2008).

Además, los autores destacan que el valor es multidimensional; se cocrea a través de múltiples coordinaciones entre actores y arreglos institucionales, de modo que los elementos como el contexto social y la cultura determinan el concepto de valor y su cocreación en cada mercado. Finalmente, los autores mencionan que el valor es emergente; todos los actores deben intercambiar recursos dentro de un ecosistema, en este sentido, la autoorganización del ecosistema se da a través de las interacciones entre sus múltiples actores y los diversos arreglos institucionales.

\section{RESULTADOS Y DISCUSIÓN}

\subsection{Cocreación de valor para el negocio artesanal}

Debido a la complejidad y el ecosistema de las artesanías es complejo y particularmente diferente ya que el intercambio de valor está envuelto de diversas particularidades, basadas en la identidad cultural comunitaria directa con pueblos indígenas. En el ecosistema de las artesanías, resulta muy adecuado, ya que, aunque se apliquen las mismas estrategias y herramientas de comercialización con el máximo esfuerzo del artesano, los resultados de la aceptación y valorización del producto artesanal puede ser diferente, dependiendo del cliente y su identidad cultural. 
En segundo lugar, los autores mencionan que el valor es siempre cocreado (basado en las premisas de la lógica SD); lo cual se refiere a que el artesano no es el único responsable de generar valor en el intercambio, ya que el valor es cocreado por múltiples actores, incluyendo siempre al cliente como agente del ecosistema, además de que "los actores no pueden entregar valor, pero sí pueden participar en la creación y suministro de propuestas de valor" se refiere a que el artesano no puede "entregar valor cultural" al cliente sino que es en conjunto que se puede generar (Vargo \& Lusch, 2016). Debido a que este valor puede ser cocreado o co-destruido, es claro entonces, que los clientes como actores del ecosistema son corresponsables de crear o destruir la riqueza cultural que de forma intrínseca reflejan las artesanías para los pueblos indígenas (Vargo, Akaka, y Vaughan, 2017).

Tabla 2. Comparativo entre la cocreación de valor y cooperación empresarial en el ecosistema de artesanías

\begin{tabular}{|c|c|c|c|}
\hline $\begin{array}{c}\text { Características del } \\
\text { ecosistema de servicio de } \\
\text { las artesanías }\end{array}$ & $\begin{array}{c}\text { Cooperación } \\
\text { para la } \\
\text { competitividad }\end{array}$ & $\begin{array}{l}\text { Axiomas de la } \\
\text { Lógica } \\
\text { dominante de } \\
\text { servicio }\end{array}$ & $\begin{array}{l}\text { Aplicación de la } \\
\text { (LDS) en la industria } \\
\text { de las artesanías }\end{array}$ \\
\hline $\begin{array}{l}\text { La cultura de los pueblos } \\
\text { indígenas se caracteriza por su } \\
\text { idiosincrasia (emociones, } \\
\text { religiosidad, cosmovisión) } \\
\text { por lo que la artesanía busca } \\
\text { generar valor en uso, } \\
\text { mediante la preservación de la } \\
\text { cultura, la producción y la } \\
\text { comercialización conjunta. }\end{array}$ & $\begin{array}{l}\text { Enfoque basado } \\
\text { en el logro de una } \\
\text { ventaja } \\
\text { competitiva para } \\
\text { la rentabilidad } \\
\text { empresarial. }\end{array}$ & $\begin{array}{l}\text { Axioma 1. El } \\
\text { servicio es la } \\
\text { base fundamental } \\
\text { del intercambio } \\
(2008)\end{array}$ & $\begin{array}{l}\text { El intercambio de valor } \\
\text { está en la interacción y } \\
\text { colaboración interna, } \\
\text { continua y dinámica, } \\
\text { mediante } \\
\text { conocimientos, técnicas } \\
\text { de fabricación, y } \\
\text { comercialización entre } \\
\text { los artesanos, así como } \\
\text { del valor en uso de los } \\
\text { clientes. }\end{array}$ \\
\hline
\end{tabular}

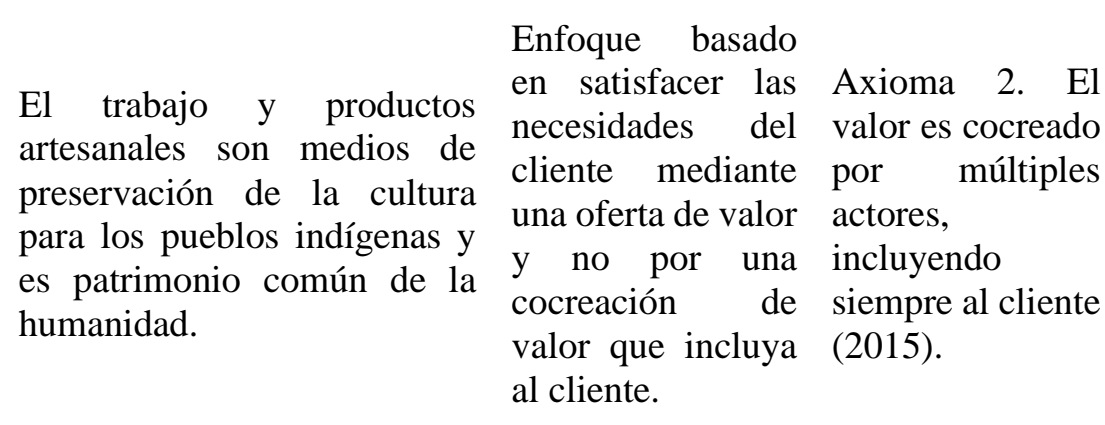

Enfoque basado en satisfacer las necesidades del cliente mediante una oferta de valor $\mathrm{y}$ no por una valor que incluya al cliente.

La cultura de los pueblos indígenas se caracteriza por su religiosidad, cosmovisión) por lo que la artesanía busca mediante la preservación de la cultura, la producción y la preservación de la es patrimonio común de la humanidad.
El comprador de una artesanía es un beneficiario del intercambio de valor, ya que el valor en uso del servicio potencializa la identidad cultural propia, o de la cultura de la cual obtiene una artesanía. 
Existe una proveeduría regional sustentable $\mathrm{y}$ autosuficiente para el desarrollo comunitario mediante el conocimiento $\mathrm{y}$ recursos que se han transmitido de generación en generación.
Enfoque basado Axioma en el volumen de Todos producción y agentes sociales venta para lograr y económicos una mayor son integradores competitividad y de recursos rentabilidad.
La participación de diferentes organizaciones sociales 3. de los pueblos os originarios $\mathrm{y}$ gubernamentales son impulsores y actores que participan mediante recursos para el funcionamiento $\mathrm{y}$ permanencia del negocio de las artesanías.

El valor no es creado mediante una "oferta de valor por parte del artesano" sino que es cocreado desde su fabricación, durante la comercialización y posteriormente durante el uso, cuando el comprador integra su conocimiento,

aprendizaje $\quad \mathrm{y}$ emociones culturales, como parte del valor de la artesanía.

Existe una multicoordinación regional propia de los pueblos indígenas (usos y costumbres), así como un impulso del gobierno local y del estado. El valor es cocreado a través de la sinergia que exista entre estos,
Su función de producción, comercialización y uso de artesanías está determinada a nivel social y cultural y no únicamente con fines comerciales y/o económicos.
Enfoque basado económica para lograr competitividad reflejada en la participación de mercado.
Axioma 5. $\mathrm{La}$ cocreación de valor se coordina a través de instituciones $y$ acuerdos institucionales generados por los actores (2015).

\section{Elaboración propia con base en (Vargo y Lusch, 2017)}

Es claro entonces que para generar una cocreación de valor en el ecosistema de servicio de las artesanías en México, resulta sentar las bases de su gestión en un enfoque que considere sus características de forma integral. El enfoque de cooperación para la competitividad ha sido aplicado con resultados favorables en diversas industrias, mayormente entre grandes empresas multinacionales que buscan la cooperación para 
lograr objetivos comerciales y de posicionamiento de forma conjunta como se observa en la Tabla 2.

Sin embargo, los pueblos indígenas, quienes son artesanos (artistas) comercializando entienden el éxito de forma diferente, buscan un beneficio mutuo entre todos los actores de su comunidad basado un criterio de sostenibilidad y respeto a su entorno social y ambiental, más que solo vender, buscan que su cultura permanezca en el tiempo.

Con base en lo anterior, los autores toman como base el enfoque de cocreación y las 6 Axiomas principales de la LDS y su aplicabilidad en el negocio de artesanías, como una propuesta de aplicación que dé lugar a un marco más integral que busque objetivos comerciales, pero considerando la idiosincrasia de los pueblos indígenas, esta aplicabilidad es presentada en la figura 3, basado en el modelo de cocreación de valor en ecosistemas de servicio dentro de la teoría de (LDS).

Figura 3. Aplicabilidad de la LDS en el ecosistema de negocios artesanales para generar cocreación de valor

\section{Ecosistema de}

Servicio

Estructurado por sus actores y su valor intrínseco

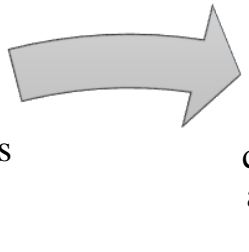

Co-creación de valor en la industria de artesanías

\section{Actores}

Artesanos y /o comercializadores de artesanías, clientes y organizacuiones

\section{Arreglos institucionales}

Usos y costumbres, reglas regionales, instituciones de gobierno a todos sus niveles

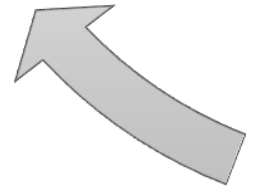

Intercambio de servicio

Valor cultural, representatividad regional y preservación de los pueblos indígenas

\section{Integración de recursos}

Conocimiento, valor cultural intrínseco, reconocimiento $\mathrm{e}$ identidad cultural

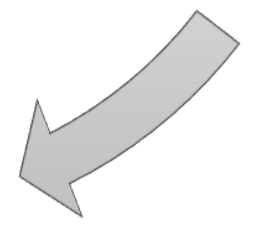

Elaboración propia con base en (Vargo y Lusch, 2017) 
El modelo de cocreación de Vargo y Lusch (2017), permite considerar la importancia de la colaboración entre todos los actores del ecosistema, mediante la integración de sus conocimientos, habilidades y aprendizajes, desde la perspectiva artesano, cliente e instituciones sociales. Lo anterior, sienta las bases para entender con mayor profundidad el negocio artesanal en México, contribuyendo a cumplir los objetivos de los pueblos indígenas como principales exponentes de la cultura e identidad regional y nacional y al mismo tiempo generar estrategias de negocio sostenibles para el desarrollo comunitario.

\section{CONCLUSIÓN O CONSIDERACIONES FINALES}

El análisis permite identificar que las artesanías vistas como producto comercial, no ha mostrado resultados de éxito, rentabilidad o competitividad para los artesanos, los pueblos indígenas o los agentes dentro del ecosistema. El verdadero valor de las artesanías radica en la representación de la cultura, en México algo que forma parte de la misma identidad nacional mexicana. Las diferentes formas de cooperación empresarial no han resultado aplicables completamente en el ecosistema de servicio de los negocios artesanales, debido su enfoque y estandarización de la ideología empresarial basado en un modelo económico fundamentado en la competitividad y desarrollo económico.

Dentro del contexto del mercado de las artesanías, el cambio de paradigma puede sentar las bases para repensar las estrategias de competitividad empresarial genéricas, por estrategias de cocreación que consideren la complejidad y las características únicas que tiene tanto la producción, comercialización y uso de las artesanías, al ser una representación cultural de los pueblos indígenas, quienes con base en su propia visión, idiosincrasia y conocimientos, buscan un desarrollo para los miembros de la comunidad (Girón, León y Hernández, 2007).

En este ecosistema complejo de negocios, el cual no considera la parte sostenible de la propia preservación de la cultura de los pueblos indígenas, siendo una gran área de oportunidad cambiar de un enfoque tradicional o que persigue una hegemonía comercial a repensar en un esquema de negocios que sea beneficio mutuo de cocrear valor entre los diferentes actores del ecosistema de negocios artesanales.

Debido a que el valor es generado por múltiples actores durante el servicio, mediante una coproducción, especialmente cuando los bienes están implicados en la creación de este valor tal como en el mercado de las artesanías, ya que aun cuando el producto "Artesanía" juega un papel importante durante el intercambio, el mayor valor se encuentra en lo que 
el bien representa de forma intrínseca "Cultura del Pueblo Indígena", y es mediante el valor en uso, en el que "toma vida" el valor de la representatividad cultural, tanto para el artesano y/o comercializador como para el comprador.

La industria de las artesanías en México está principalmente enmarcada por los valores simbólicos e ideología comunitaria, en la que el conocimiento y técnicas de fabricación que pasa de generación en generación no solo representa su modo de vida, sino la forma de preservar su cultura. Por tanto, estos recursos, y su estructura social, constituyen la esencia de los pueblos indígenas, y son sin duda elementales en el "valor en uso" que las artesanías tienen para los productores, vendedores y compradores. El enfoque pasa de crear productos artesanales que satisfagan las necesidades del cliente influenciados por las culturas dominantes a coproducir valor entre los consumidores y los diferentes actores del ecosistema.

Con base a lo anterior, no se habla de comercializar la cultura, como se ha pensado bajo una premisa de competitividad, se busca que el modelo de negocio, coexista en un ecosistema que favorezca la sostenibilidad, dejando ganancias por la comercialización, un intercambio de valor en uso para el rescate de la cultura y un entendimiento de la naturaleza de la propia artesanía, sus materias primas y el cuidado del medio ambiente.

Un ecosistema de servicio como el de las artesanías en México, requiere de una gestión integral (Lógica Dominante de Servicio) enfocada a comprender su naturaleza, idiosincrasia y valor cultural, mediante un marco más amplio para el estudio de la complejidad y particularidad del ecosistema. El enfoque basado en el servicio está sentado las bases para el macromarketing, concepto que integra la ética, la sostenibilidad económica, medioambiental y social así como las políticas públicas, lo cual resulta un enfoque óptimo para la gestión estratégica de las artesanías, un novedoso enfoque que va más allá de cooperar para ser competitivos, como lo hacen las grandes empresas, sino como los artesanos ven una oportunidad en los negocios, para genera ingresos y salvaguardar su cultura, mediante estrategias sostenibles para el desarrollo comunitario.

\section{LISTA DE REFERENCIAS}

Arcas, N., Hernández, M. y Munuera, J. (2000). La relación entre las cooperativas agrarias de primer y segundo grado desde la perspectiva del marketing de relaciones y redes: una propuesta de un modelo de estudio. CIRIEC- España. Revista de Economía Pública, Social y Cooperativa. No. 36; pp. 179-202. 
Cantillo Campo, N., Paz Marcano, A., y Ojeda Hidalgo, J. (2021). Marketing verde en Pymes comercializadoras y distribuidoras de artesanía Wayúu. Desarrollo Gerencial, 13(1).

Ciria, M. (2014). Clúster del conocimiento: Oportunidad de mejora competitiva. Tesis de Maestría en Administración y Dirección de Empresas. Universidad de Valladolid. Recuperado de: http://uvadoc.uva.es/handle/10324/5982

Constantinides, E. (2006). The Marketing Mix Revisited: Towards the 21st Century Marketing. Journal Of Marketing Management, 22(3/4), 407-438.

Díaz-Méndez, M., Saren, M., \& Gummesson, E. (2017). Considering pollution in the higher education (HE) service ecosystem: The role of students' evaluation surveys. The TQM Journal.

Dini, M. (2010). Competitividad, redes de empresas y cooperación empresarial. Serie de Gestión Pública. Naciones Unidas, CEPAL. Vol. 1 No. 72 ; pp. 1-102.

Dollinger, M., Lodge, J., \& Coates, H. (2018). Co-creation in higher education: Towards a conceptual model. Journal of Marketing for Higher Education, 28(2), 210-231.

Echevarría, C. A., Aguirre, M. S., \& Aparicio, M. G. (2014). Orígenes, elementos determinantes y resultados de un exitoso proceso de colaboración entre competidores y otros agentes: el cluster de la Alta Cocina Vasca. Management Letters/Cuadernos de Gestión, 14(2), 51-72.

Ferrel, O. y Hartline, M. (2012). Estrategia de Marketing. Cengage Learning Editores, S.A. de C.V. Quinta edición. México, DF. pp 41-45.

García Canclini, N. (1999). Los usos sociales del patrimonio cultural. Consejería de Cultura. Junta de Andalucía.

Girón, J. D. L. P. H., León, M. Y., \& Hernández, M. L. D. (2007). Factores de éxito en los negocios de artesanía en México. Estudios gerenciales, 23(104), 77-99.

Guatzozón Maldonado, M., Canto Esquivel, A. M., y Pereyra Chan, A. (2020). Calidad en el servicio en micronegocios del sector artesanal de madera en una comisaría de Mérida, México. Ingeniare. Revista chilena de ingeniería, 28(1), 120-132.

Hernández, J., Domínguez, M. \& Ramos, A. (2002). Canales de Distribución y competitividad en Artesanias. Espiral, vol. IX, núm. 25, septiembre-diciembre, Universidad de Guadalajara, Guadalajara, México. ISSN: 1665-0565 
Javidan, M. (1998). Core competence: What does it mean in practice? Long Range Planing. Vol. 31. No.1.

Jiménez, J., Domínguez, Ma. y Martínez, C. (2009). Estrategias y competitividad de los negocios de Artesanía en México. ISSN:1657-6276. Pensamiento y Gestión. Universidad del Norte, Vol (26), pp165-190.

Kotler P. \& Armstrong G. (2012) Marketing, decimocuarta edición, Pearson Educación. México.

Kotler P. \& Keller K. (2012) Dirección de Marketing. Decimocuarta edición. Pearson Education. México

Kotler, P., Pfoertsch, W., \& Sponholz, U. (2021). Rethinking Operative Marketing: The H2H Process. In H2H Marketing (pp. 157-216). Springer, Cham.

Lusch, R. F., \& Vargo, S. L. (2006). Service-dominant logic: reactions, reflections and refinements. Marketing theory, 6(3), 281-288.

Lusch, R. F., Vargo, S. L., \& O’brien, M. (2007). Competing through service: Insights from service-dominant logic. Journal of retailing, 83(1), 5-18.

Lusch, R. F., Vargo, S. L., \& Gustafsson, A. (2016). Fostering a trans-disciplinary perspectives of service ecosystems. Journal of Business Research, 69(8), 29572963.

Nie, Z., Zurlo, F., Camussi, E., \& Annovazzi, C. (2019). Service ecosystem design for improving the service sustainability: A case of career counselling services in the Italian higher education institution. Sustainability, 11(5), 1427.

OIT (1989) Convenio núm. 169 sobre los pueblos indígenas y tribiales. Oficina Internacional del Trabajo. Ginebra. Recuperado de https://www.ilo.org/wcmsp5/groups/public/---americas/---rolima/documents/publication/wcms_345065.pdf

ONU (2021). Los Pueblos Indígenas en las Naciones Unidas. Departamento de Asuntos Económicos y Sociales, Pueblos Indígenas, Organización de las Naciones Unidas. Recuperado de: https://www.un.org/development/desa/indigenous-peopleses/historia.html

ONU (2021). Día Internacional de los Pueblos Indígenas 9 de agosto. Organización de las Naciones Unidas. Recuperado de: https://www.un.org/es/observances/indigenous-day 
Perks, H., Gruber, T., \& Edvardsson, B. (2012). Co-creation in radical service innovation: a systematic analysis of microlevel processes. Journal of product innovation management, 29(6), 935-951.

Peña, M. L. M., \& Garrido, E. D. (2016). Fundamentos de dirección de operaciones en empresas de servicios. ESIC Editorial.

Porter, M. E. (1990). Clústers and Competition. New Agenda for Companies. In Governments and Institutions, New York: Free Press. On Competition. Vol.1 pp. 197-287

Porter, M. E. (1997). Competitive strategy. Measuring business excellence.

Robles, Romero y García (2007). Manual de Diferenciación entre Artesanía y Manualidad. FONART. México. Peña, M. L. M., \& Garrido, E. D. (2016). Recuperado

de:https://www.gob.mx/cms/uploads/attachment/file/107963/Manual_diferencia cion_artesania_manualidad_2015.pdf

Sales, F. (2013). Las artesanías en México, situación actual y retos. Centro de Estudios Sociales y de Opinión Pública (CESOP) Cámara de Diputados/ LXII Legislatura.México. $\quad$ pp. 10-57. Recuperado http://www5.diputados.gob.mx/index.php/camara/Centros-de-

Estudio/CESOP/Estudios-e-Investigaciones/Libros/Las-artesanias-en-Mexico.Situacion-actual-y-retos

Sánchez, D., González, P. y Jiménez, E. (2007). La cooperación empresarial como estrategia de crecimiento: motivos de su formación, ventajas e inconvenientes. Decisiones basadas en el conocimiento y en el papel social de la empresa: XX congreso Anual AEDEM. Vol (2); pp 30. Recuperado de http://dialnet.unirioja.es/servlet/articulo? codigo=2499441

UNESCO (1997). Simposio UNESCO/CCO "La artesanía y el mercado internacional: comercio y codificación aduanera" Manila. Organización de las Naciones Unidas para la Educación, la ciencia y la cultura. Recuperado de http://portal.unesco.org/culture/es/ev.phpURL_ID=35418\&URL_DO=DO_TOPIC\&URL_SECTION=201.html

Vargo, S. L., \& Akaka, M. A. (2009). Service-dominant logic as a foundation for service science: clarifications. Service Science, 1(1), 32-41. 
Vargo, S. L., Akaka, M. A., \& Vaughan, C. M. (2017). Conceptualizing value: a serviceecosystem view. Journal of Creating Value, 3(2), 117-124.

Vargo, S. L., \& Lusch, R. F. (2004). Evolving to a new dominant logic for marketing. Journal of marketing, 68(1), 1-17.

Vargo, S. L., \& Lusch, R. F. (2008). Service-dominant logic: continuing the evolution. Journal of the Academy of marketing Science, 36(1), 1-10.

Vargo, S. L., \& Lusch, R. F. (2014). Service-dominant logic: What it is, what it is not, what it might be. In The service-dominant logic of marketing (pp. 61-74). Routledge.

Vargo, S. L., \& Lusch, R. F. (2017). Service-dominant logic 2025. International Journal of Research in Marketing, 34(1), 46-67.

Vargo, S. L., Lusch, R. F., Akaka, M. A., \& He, Y. (2020). Service-dominant logic. The Routledge Handbook of Service Research Insights and Ideas, 3.

Zúñiga, C. R., Toro, G. Z., \& Gámez, A. S. (2016). Técnicas de marketing en las empresas de artesanías wayuu en el distrito turístico y cultural de Riohacha, Guajira, Colombia. Omnia, 22(3), 87-99. 